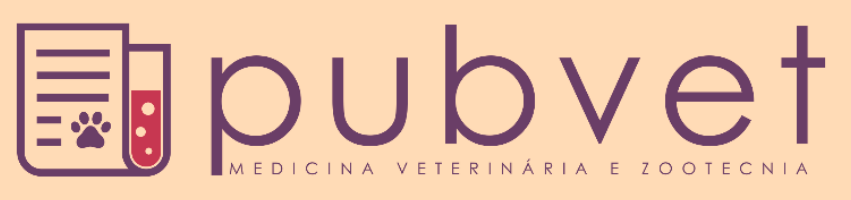

https://doi.org/10.31533/pubvet.v14n3a540.1-4

\title{
Farmacodermia em uma cadela após a administração de prometazina: relato de caso
}

\author{
Alessandra Ramon Mastrocinque* \\ * Médica veterinária, graduanda no Programa de Pós-graduação de Dermatologia Veterinária da Universidade Anhembi Morumbi. E-mail: \\ ale.medicaveterinaria@hotmail.com
}

Resumo. O presente trabalho teve por objetivos relatar a ocorrência da farmacodermia em uma cadela, sem raça definida de aproximadamente quatro anos após a administração de cloridrato de prometazina por via subcutânea na dose preconizada de $0,2 \mathrm{mg} / \mathrm{kg}$. Ainda, descrever as principais lesões, o seu tratamento e prognostico, por se tratar de uma afecção de rara ocorrência em cães e gatos.

Palavras-chave: cloridrato de prometazina, farmacodermia

\section{Pharmacoderma in dog after promethazine administration: case report}

Abstract. The objective of the present study was to report the occurrence of pharmacodermia in a female, non-bred bitch approximately 4 years after subcutaneous administration of promethazine hydrochloride at the recommended dose of $0.2 \mathrm{mg} / \mathrm{kg}$. Still, describe the main aspects of lesions, its treatment and prognosis, as it is a rare condition in dogs and cats.

Keywords: pharmacordemia, promethazine hydrochloride

\section{Farmacodermia en una perra después de la administración de promethazine: reporte de un caso}

Resumen. El objetivo del presente estudio fue informar la aparición de farmacodermia en una hembra canina, criolla, de aproximadamente 4 años después de la administración subcutánea de clorhidrato de prometazina a la dosis recomendada de $0.2 \mathrm{mg} / \mathrm{kg}$ y describir los aspectos principales de lesiones, su tratamiento y pronóstico, ya que es una condición rara en perros y gatos.

Palabras clave: Clorhidrato de prometazina, farmacoderma

\section{Introdução}

A farmacodermia ou erupção medicamentosa é uma doença mucocutânea, pleomórfica, de natureza recidivante, variavelmente pruriginosa e algumas vezes acompanhada por sinais sistêmicos, cujas lesões cutâneas são de tipos e configurações variáveis (Festa Neto et al., 1990; Larsson, 1996). As reações adversas cutâneas são classificadas em previsíveis, quando são dose-dependente e se relacionam as ações farmacológicas do medicamento, e em imprevisíveis, as quais são independentes da dose e se relacionam à resposta imune ou à suscetibilidade do indivíduo (Hnilica \& Medleau, 2012; Scott et al., 1996).

Apesar de esta condição ser considerada rara, a gravidade de alguns casos torna preocupante a hipótese de sua ocorrência (Cardoso et al., 2011; Larsson, 1996). Estima-se que a incidência da farmacodermia seja de aproximadamente 1,6\% e 2,0\% em gatos e cães com distúrbios dermatológicos, respectivamente (Scott \& Miller Junior, 1998). 
Dentre as farmacodermias, algumas manifestações particulares podem ser reações listradas no ponto da aplicação, erupção máculo-papular, eritema fixo, eritema polimorfo, eritrodermia, erupções vesiculos-bolhosas-pustulares, erupções liquenoides, vasculite, necrosile epidérmica toxica, extravasamento de medicamentos e por fim angioedema e urticaria (Mencalha, 2019).

É reconhecido que a ocorrência de uma reação farmacodérmica pode mimetizar diferentes dermatoses (Wilkinson \& Harvey, 1997) e que, portanto, torna-se fundamental o adequado conhecimento dos medicamentos administrados a qualquer paciente que venha a apresentar dermatopatia (Alam, 2004). As lesões cutâneas podem se desenvolver após dias ou anos de uso do medicamento, ou, ainda, após sua suspensão (Alam, 2004; Scott et al., 1996).

A identificação do agente etiológico da farmacodermia pode ser difícil, visto que muitos pacientes recebem diversos medicamentos simultaneamente (Affolter \& Von Tscharner, 1993). Para diagnóstico de erupção causada por medicamentos, o único teste confiável é a suspensão do fármaco com remissão da lesão. Subsequentemente, a re-administração do medicamento de forma proposital, embora perigosa, poderá determinar se ocorrerá reprodução das lesões indesejáveis (Manson, 1990; Scott et al., 1996).

A reação cutânea a drogas produz uma grande variação nos sinais tegumentares, o que torna o diagnóstico diferencial ainda mais complexo. A descontinuidade na administração do fármaco e o aguardo do desaparecimento dos sinais é o único teste confiável (Miller et al., 2013). O diagnóstico é baseado na anamnese minuciosa, reexposição ao fármaco assumindo os riscos (Mencalha, 2019).

Dentre os testes reportados na bibliografia incluem-se: teste de liberação histamínica, teste de degranulação basofilica, teste de hemaglutinação passiva, prova de transformação blástica de linfócitos (na presença da droga), todos eles, com resultados poucos conclusivos, bem pouco exequíveis e disponíveis nas condições brasileiras. Dos exames subsidiários, aquele mais viável, permitindo que se estabeleça o diagnóstico etiológico é o exame histopatológico de fragmentos de pele biopsiada, de aeras eritematoso, erosadas, ulceradas, descamativa ou encrostadas (Ettinger et al., 2002; Feldman, 1997).

Os padrões histopatológicos referidos são dermatite perivascular, dermatite de interface, dermatite vesicobolhosa, necrose folicular, dermatite intersticial e paniculite (Ettinger et al., 2002; Feldman, 1997). Segundo Mencalha (2019) podemos incluir também acantólise, infiltrado perivascular em derme espongiotica e hiperplásica.

$\mathrm{O}$ tratamento consiste na interrupção da administração do medicamento suspeito associado à terapia sintomática. Em algumas situações pode ser necessária a utilização de glicocorticoides e segundo Ettinger et al. (2002) e Feldman (1997) ainda podemos usar imunomodulares como ciclosfofamida, ciclosporina, azitioprina e pentoxifilina. É importante evitar o uso de drogas quimicamente relacionadas (Wilkinson \& Harvey, 1997).

O prognostico é bom se não houver reutilização do fármaco e se não houver necrose extensa e comprometimento de órgãos (Mencalha, 2019). O prognostico quanto a evolução, a cura e à vida no geral é bom, na maioria das formas clínicas da farmacodermia. Uma vez estabelecido o diagnóstico, preferencialmente precoce, e interrompida a medicação, há remissão gradativa, em uma ou duas semanas do quadro (Ettinger et al., 2002; Feldman, 1997).

\section{Relato de caso}

Este artigo visa relatar um caso de farmacodermia em uma cadela, fêmea, sem raça definida de aproximadamente quatro anos. $\mathrm{O}$ animal apresentou reação localizada ulcerativa e pontos de necrose após a aplicação de medicação para controle de prurido.

Verificou-se que o animal havia sido medicado com cloridrato de prometazina $25 \mathrm{mg} / \mathrm{ml}$ ampola por via subcutânea na dose de $0,2 \mathrm{mg} / \mathrm{kg}$, sendo a dose preconizada de $0,2-0,4 \mathrm{mg} / \mathrm{kg}$.

Durante o exame clínico não se notaram demais alterações clínicas além de lesão ulcerativa com sinais de necrose localizada.

Cerca de dois dias após a aplicação na data de 26/08/2018 o animal apresentou ferida no local da aplicação, sem prurido ou qualquer outra alteração clínica. A ferida se iniciou com quedas de pelo no local da aplicação, evoluindo para ferida aberta (․ㅏo 1$)$. 
Iniciamos o tratamento com limpeza da ferida com clorexidina a cada doze horas e após a limpeza introduzimos a pomada para cicatrização PSK - repair system (soft care) a cada 12 horas. Após três dias somente com a pomada houve uma piora da ferida (Foto 2) relacionada com a lambedura excessiva do animal, mantivemos a pomada PSK e finalizamos com curativo de gaze e faixa para evitar a lambedura da ferida.

No próximo retorno em três dias já notamos uma diminuída na extensão da ferida porem continha secreção com pus (Foto 3), sendo instituído ao tratamento Amoxicilina com clavulanato de potássio V.O na dose de $15 \mathrm{mg} / \mathrm{kg}$ BID por 7 dias associado com prednisolona $1 \mathrm{mg} / \mathrm{kg}$ SID por 5 dias. Após os 7 dias de tratamento não havia mais secreção (Foto 4), retirando a amoxicilina e mantivemos a prednisolona para desmame no total de 10 dias de tratamento, havendo uma melhora significante e fechamento parcial da ferida (Foto 5). Mantivemos a limpeza com clorexidina e aplicação da pomada PSK repair system (soft care) até remissão da ferida na data de 22/09/2018. Realizado mais um retorno após 30 dias onde visualizamos remissão total da ferida; porém, sem surgimento de pelos no local da aplicação (Foto 6).

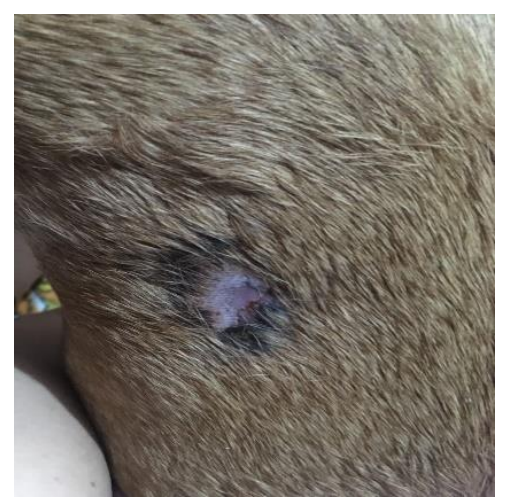

Foto 1. 2 dias após aplicação (26/07/2018).

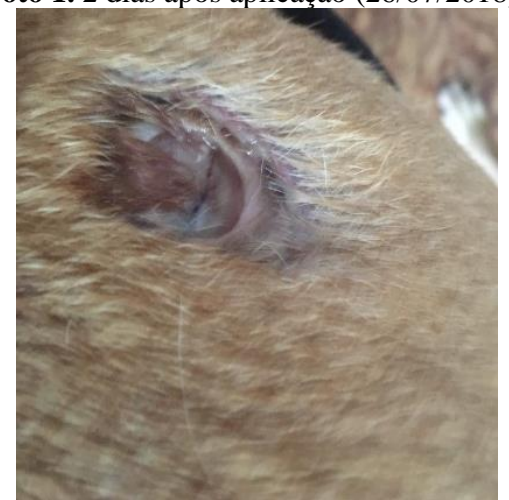

Foto 3. Ferida com secrecão.

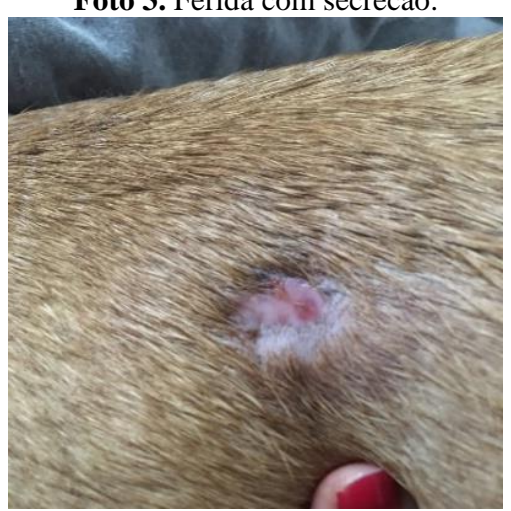

Foto 5. ferida em cicatrização.

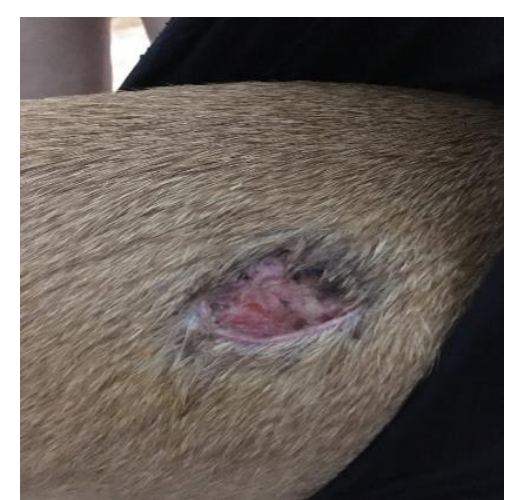

Foto 2. 5 dias após aplicação

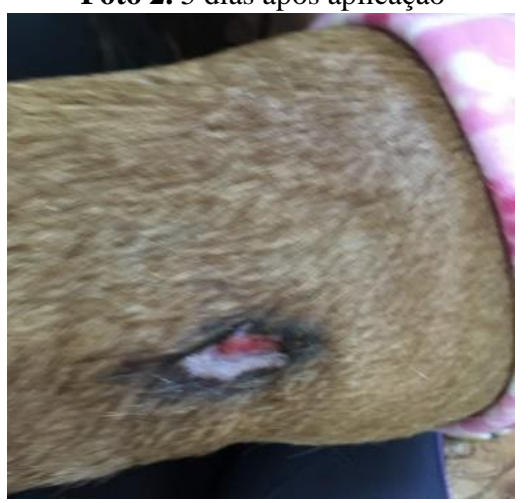

Foto 4. Ferida em processo de cicatrização sem secreção.

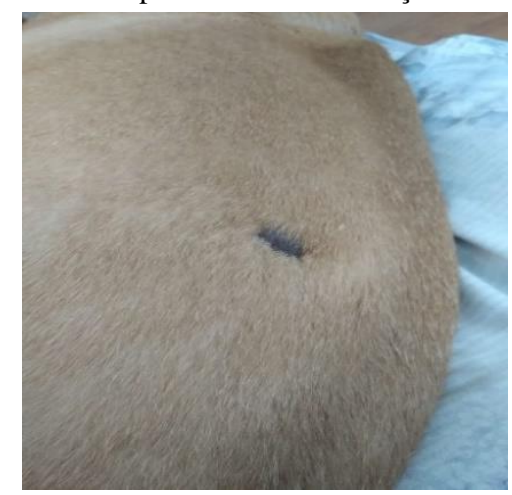

Foto 6. ferida cicatrizada porem sem surgimento de pelos. 


\section{Considerações finais}

Apesar da farmacodermia ser uma condição rara na rotina veterinária, o clínico precisa saber da sua ocorrência e estar claro que qualquer grupo de medicamentos, sendo eles tópicos, injetáveis ou orais pode ocasionar a farmacodermia. Apesar de na maioria dos casos os sintomas serem leves e se resolverem após a suspensão do medicamento da causa, existem algumas condições mais graves que podem comprometer a vida do animal.

Seu diagnóstico é difícil e necessita de uma boa anamnese pois a farmacodermia pode ocorrer meses após a exposição da medicação e não tendo um exame específico para confirmar, ainda tem autores que digam que a reexposição ao fármaco pode fechar o diagnostico porem seria um procedimento arriscado. Para seu tratamento podemos usar medicamentos imunomoduladores e a suspensão imediata do medicamento desde que isso não comprometa a vida do animal.

\section{Referências bibliográficas}

Affolter, V. K., \& Von Tscharner, C. (1993). Cutaneous drug reactions: a retrospective study of histopathological changes and their correlation with the clinical disease. Veterinary Dermatology, 4(2), 79-86.

Alam, M. (2004). Fitzpatrick's dermatology in general medicine. Archives of Dermatology, 140(3), 372.

Cardoso, M. J. L., Machado, L. H. A., Melussi, M., Zamarian, T. P., Carnielli, C. M., \& Júnior Ferreira, J. C. M. (2011). Dermatopatias em cães: revisão de 257 casos. Archives of Veterinary Science, 16(2), 66-74.

Ettinger, S. J., Fedlman, E. C., \& Taibo, R. A. (2002). Tratado de medicina interna veterinaria: enfermedades del perro y el gato. Manole.

Feldman, E. C. (1997). Tratado de medicina interna veterinária. In Moléstias do cão e do gato (Vol. 3).

Festa Neto, C., Forlani, L. X. R., Haddad, E. S., \& Souza, P. K. (1990). Farmacodermia: aspectos epidemiológicos, tipos clínicos e agentes causais. Anais Brasileiro de Dermatologia, 65(3), 125-128.

Hnilica, K. A., \& Medleau, L. (2012). Dermatologia de pequenos animais: atlas colorido e guia terapêutico. Roca.

Larsson, C. E. (1996). Dermatopatias alérgicas-hipersensibilidade medicamentosa (HM). Clínica Veterinária, 5(1), 351-355.

Manson, K. V. (1990). Cutaneous drug eruptions. Veterinary Clinics of North America: Small Animal Practice, 20, 1633-1653.

Mencalha, R. (2019). Atls de dermatologia em cães e gatos de A a Z. Medvep.

Miller, W. H., Griffin, C. E., Campbell, K. L., \& Muller, G. H. (2013). Muller and Kirk's Small Animal Dermatology. Elsevier Health Sciences.

Scott, D W, \& Miller Junior, W. H. (1998). Idiosyncratic cutaneous adverse drug reactions in the cat: literature review and report of 14 cases (1990-1996). Feline Practice, 26, 10-18.

Scott, Danny W, Muller, G. H., \& Kirk, R. W. (1996). Dermatologia dos pequenos animais (Vol. 1). Interlivros.

Wilkinson, G. T., \& Harvey, R. G. (1997). Atlas colorido de dermatologia dos pequenos animais: guia para o diagnóstico (Vol. 1). Manole Ltda.

Recebido: 21 de novembro, 2019.

Aprovado: 23 de dezembro, 2019.

Publicado: 24 de abril, 2020.

Licenciamento: Este artigo é publicado na modalidade Acesso Aberto sob a licença Creative Commons Atribuição 4.0 (CC-BY 4.0), a qual permite uso irrestrito, distribuição, reprodução em qualquer meio, desde que o autor e a fonte sejam devidamente creditados. 